\title{
BMJ Open Trend study on the association between hospital admissions and the health of Dutch older adults (1995-2009)
}

\author{
Henrike Galenkamp, ${ }^{1}$ Dorly J H Deeg, ${ }^{1,2}$ Renate T de Jongh, ${ }^{3}$ \\ Jan W P F Kardaun, ${ }^{4,5}$ Martijn Huisman ${ }^{1,6}$
}

To cite: Galenkamp H, Deeg DJH, de Jongh RT, et al. Trend study on the association between hospital admissions and the health of Dutch older adults (19952009). BMJ Open 2016;6: e011967. doi:10.1136/ bmjopen-2016-011967

- Prepublication history and additional material is available. To view please visit the journal (http://dx.doi.org/ 10.1136/bmjopen-2016011967).

Received 23 March 2016 Revised 14 July 2016 Accepted 22 July 2016

\section{CrossMark}

\footnotetext{
${ }^{1}$ Department of Epidemiology and Biostatistics and the EMGO Institute for Health and Care Research, VU University Medical Center, Amsterdam, The Netherlands 2Department of Psychiatry, VU University Medical Center, Amsterdam, The Netherlands ${ }^{3}$ Department of Internal Medicine, VU University Medical Center, Amsterdam, The Netherlands

${ }^{4}$ Statistics Netherlands, The Hague, The Netherlands ${ }^{5}$ Department of Public Health, Academic Medical Center, Amsterdam, The Netherlands ${ }^{6}$ Department of Sociology, VU University, Amsterdam, The Netherlands
}

Correspondence to Dr Henrike Galenkamp; h.galenkamp@vumc.nl

\section{ABSTRACT}

Objectives: An increase in hospital admission rates in older people may reflect improved access to healthcare, but also declining health trends in the older population. Owing to a lack of individual-level data, the latter possibility has received little attention. The current study examines associations between health status and hospitalisation rates of older adults in the Netherlands.

Design: Observational individual-level data linked to hospital register data.

Setting: Data from 1995 to 2009 from the nationally representative Longitudinal Aging Study Amsterdam were linked to the Dutch Hospital Discharge Register.

Participants: A total of 5681 observations of 2520 respondents across 4 measurement points (each with a follow-up of 36 months; ages 65-88 years).

Outcome measures: The contribution of health, demographic, psychosocial and lifestyle characteristics to time trends in hospitalisation was assessed in multivariate models.

Results: Between 1995 and 2009, the percentage with 1 or more overnight admissions (planned or acute) increased slightly from $38.1 \%$ to $39.7 \%$. This was due to an increase in acute admission only (22.2-27.0\%). Increased prevalences of chronic diseases, functional limitations and polypharmacy accounted for part of the observed increase in acute admissions. In addition, a more than doubled prevalence of day admissions over time was observed (12.3-28.3\%), a trend that was unrelated to changes in individual characteristics.

Conclusions: This trend study showed a contribution of declines in population health to increases in acute hospital admissions. Since these declines did not provide a full explanation, healthcare reforms and increases in treatment possibilities in this period are likely to have contributed as well.

\section{INTRODUCTION}

With the ageing population in most Western countries, there is increasing pressure to reduce healthcare expenditures. Hospital care is the most costly type of care ${ }^{1}$ and for the greater part involves older adults. Pressures for cost containment as well as the

\section{Strengths and limitations of this study}

- The Longitudinal Aging Study Amsterdam is a cohort study that is representative of the Dutch older population.

- Multiple waves of data collection, within two different cohorts, were performed between 1995 and 2006, which enabled the study of health trends.

- While previous studies mostly relied on aggregated data, our study links individual-level data on health and lifestyle trends to individual-level hospital registration data.

- The coverage of the Dutch Hospital Discharge Register decreased during our study period.

- Health status characteristics and hospital admission were linked per individual, but it remains to be studied if and to what extent the health status of patients at the time of their admission has changed.

introduction of new medical technologies have resulted in a reduced length of stay in most developed countries in recent decades. ${ }^{2} 3$ Another approach to cost containment may be prevention of hospitalisation and adverse events related to hospital admissions, ${ }^{4}$ but several studies-not all ${ }^{5}$ show increases in hospital admission rates and hospital costs in European countries and the USA over the past decades. ${ }^{6-9}$

Both individual and societal factors may affect the usage of hospital care. ${ }^{10}$ Research addressing the mechanisms underlying increased use of care and increased healthcare expenditures showed that these are largely driven by societal changes, such as improved medical technology and more active treatment of the oldest old, and only for a small part by demographic changes. ${ }^{8} 11$

Regarding individual factors, the prevalence of morbidity and disability-the most immediate causes of hospital admission ${ }^{10} 12-14$ - have shifted in recent generations of older adults. Ample evidence exists of an increased 
prevalence of chronic diseases and comorbidity over time, both in admitted patients and in older adults in the community. ${ }^{3}{ }^{15-20}$ We expect that this has led to more healthcare usage in recent decades. Research is inconclusive regarding trends in disability or in the severity of morbidity, but in the Netherlands disability trends have not been as favourable as in some other countries. ${ }^{17}{ }^{21}$ Technological developments in recent decades may have led to better treatment possibilities and, in turn, to better health, functioning and survival of older adults. Longer survival specifically in those with chronic diseases, however, leads to a higher prevalence of chronic conditions and associated hospital admission risk. Such mixed trends make it difficult to formulate a clear-cut hypothesis regarding trends in hospital admission. In particular, if one considers the variety in types of hospital admission, such as acute versus planned, and day versus overnight admissions, all of which address different healthcare needs.

Given the societal costs associated with hospital care and the burden of hospitalisation on older patients themselves, ${ }^{4}$ reducing hospital admissions among older adults is an important goal. However, simply reducing the volume of hospital care should not be aimed for when it is at the expense of poorer quality of care or an increased disease burden. In fact, reducing one type of admission (eg, day admissions) may result in more admissions of another-more critical-type (eg, acute admissions). Policies aiming at the prevention of hospitalisation should be informed by research on underlying health trends in the older population. In addition, trends in day admissions and overnight admissions (acute or planned) should be evaluated in relation to each other.

This study explores recent hospital admission trendsday admissions and overnight (planned and acute) admissions. It also examines to what extent upward or downward trends can be attributed to changing health of the older population. Individual-level health and hospital data are needed for this purpose, since these are more sensitive than population means. In addition, they may provide insight into the inter-relationships between various individual characteristics. We linked individual morbidity data from Dutch older adults between 1995 and 2009, obtained within a nationally representative cohort study on ageing, the Longitudinal Aging Study Amsterdam (LASA), with data from the Dutch Hospital
Discharge Register (DHDR), providing individual-level data on hospital admissions.

\section{METHODS}

\section{Data sources}

\section{Longitudinal Aging Study Amsterdam}

In 1992, a random sample of older adults was drawn from the population registries of 11 municipalities in three geographical regions in the Netherlands (ages 5585 years; N 3107) with a cooperation rate (the proportion of completed interviews in the number of contacted eligible persons) of $62 \% .^{22}{ }^{23}$ Follow-up measurements took place at roughly 3-year intervals in 1995-1996 and 1998-1999, 2001-2002 and 2005-2006 (figure 1). In 2002, a new cohort was sampled (ages 55-64 years; $\mathrm{N}$ 1002; cooperation rate 62\%). Complete medical records were available for the period 1995-2009; therefore, LASA participants who had at least one interview between 1995-1996 and 2005-2006 were included. Waves will be referred to using the mid-year of each follow-up (36 months): 1997, 2000, 2003 and 2007. We selected all 2520 adults who were aged $65-88$ at the time of at least one wave, to compare a fixed age range which was available in each wave. Thirty-six per cent of these respondents were included in one wave, $23 \%$ in two waves, $21 \%$ in three waves and $20 \%$ in all four waves, leading to a total number of 5681 observations.

\section{Dutch Hospital Discharge Register}

The DHDR (Landelijke Basisregistratie Zorg (LBZ), previously Landelijke Medische Registratie (LMR)) ${ }^{24}$ registers admissions in most general and academic hospitals and some single-specialty hospitals, thus providing a nearly complete coverage of hospital admissions in the Netherlands. All admissions are registered based on a uniform registration system. The data include admission and discharge dates, extensive diagnosis and treatment information and death during admission. A study on the reliability of admission and discharge information in the DHDR revealed that in 1999, 99\% of this information was registered correctly. ${ }^{25}$

\section{Linkage of data sources}

For the purpose of this study, Statistics Netherlands linked data from the DHDR and LASA to each other via the Municipal Population Registry (MPR). Both data sets

LASA - interviews:

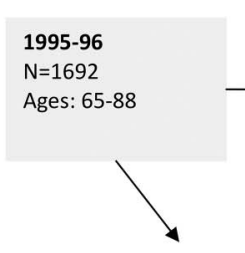

1995-1999

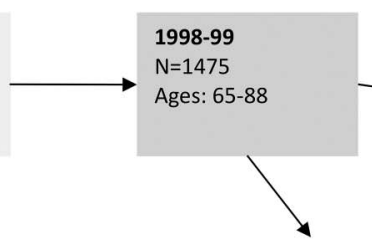

1998-2002

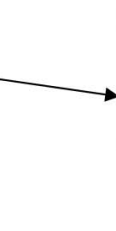

$\longrightarrow$

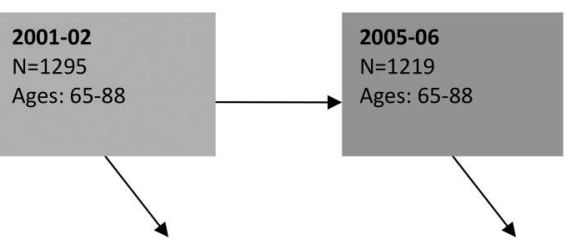

2001-2005
2005-2009

Figure 1 Study design and number of participants. LASA, Longitudinal Aging Study Amsterdam; LMR, Landelijke Medische Registratie. 
are anonymised, so this linkage occurred on the basis of a set of identifying variables: postal code, date of birth and gender. ${ }^{24}$ Linkage with the MPR was fully achieved for $98 \%$ of the eligible study sample. Consent forms for accessing medical records were signed by the LASA participants and the study was approved by the Medical Ethics Committee of the VU University Medical Center.

\section{Measurements}

Table 1 gives an overview of all study variables and how they were measured. Hospital admission within 36 months follow-up of each LASA interview was coded as not admitted (0) or admitted at least once (1). Admissions were categorised into day admission or overnight admission. Day admissions were defined as planned admissions where specialist care is given for several hours during the day. Visits to the emergency unit were not included as a day or overnight admission, unless an overnight admission followed from this visit. Overnight admissions were all admissions including at least one night. These admissions were further divided into acute or elective admissions.

To increase our understanding of which individuallevel factors underlie hospital admission trends, we assessed the role of demographic, psychosocial and lifestyle factors stepwise in addition to health status factors.

Education level was measured in years. Net monthly income of respondents living with a partner was multiplied by 0.7 to make their income comparable with that of one-person households. ${ }^{26}$ Also included were level of urbanisation (categories were $<500,500-1000,1000-1500$, $1500-2500$ and $>2500$ addresses per $\mathrm{km}^{2}$ ), marital status (married vs not married) and an indicator of being institutionalised or not.

As psychosocial variables we included mastery, assessed with a 5-item version of the Pearlin Mastery scale, ${ }^{27}$ social network size, ${ }^{28}$ the amount of instrumental and emotional support received from one's network members over the past year ${ }^{28}$ and social and emotional loneliness, assessed with the 11-item De Jong Gierveld Loneliness Scale. ${ }^{29}$

Smoking behaviour was categorised into non-smokers, former smokers or current smokers. If respondents had stopped more than 20 years ago, they were categorised as non-smokers, since studies have shown similar mortality risks for those who stopped more than 20 years ago, compared with non-smokers. ${ }^{30}$ Alcohol consumption (glasses per week) was computed by multiplying the number of days per week respondents usually drank and the number of glasses each time. ${ }^{31}$ Body mass index was calculated by dividing measured weight (in kilogram) by height (in metres) squared. Averaged daily minutes of physical activity $(P A)$ was computed by multiplying selfreported frequency and duration of activities. This computation was done separately for non-sports and sports activities. ${ }^{32}$ If the frequency or the time spent on the activity was missing, we imputed these by substituting with gender-specific and activity-specific means.
Self-reported health factors were: a count of nine chronic diseases (chronic non-specific lung disease, cardiac disease, peripheral arterial disease, stroke, diabetes mellitus, arthritis, cancer and a maximum of two other diseases that had been present for at least 3 months ${ }^{33}$ ), functional limitations, indicating the number of activities out of six that respondents reported having difficulty performing, ${ }^{34}{ }^{35}$ and self-rated health, with responses ranging from very good $(1)$ to poor $(5) .^{36}$ Previous care use was also included, defined as having had any contact with a general practitioner or a medical specialist in the previous 6 months.

Objective health measures were: physical performance, measured with three performance-based tests (walking speed, ability to rise from a chair and putting on and taking off a cardigan). ${ }^{37}$ Sum scores ranged from 0 to 12 , with 12 indicating the best performance. We included a measure of polypharmacy, that is, whether people took five or more drugs versus four or less. The number of drugs used was recorded from the medicine containers in the home of the respondents. Since there is no agreed definition of polypharmacy, ${ }^{38}$ we based our definition of polypharmacy on previous studies. ${ }^{39} 40$ Systolic and diastolic blood pressure $(B P)$ measurements were performed in sitting position. If multiple BP measurements were available (waves 2001-2002 and 2005-2006), only the first measurement was used to make the measurements comparable across waves. Depressive symptoms were measured with the Center for Epidemiologic Studies Depression Scale, ${ }^{41}$ a 20 -item scale covering depressive symptomatology in the past week. General $c o g$ nitive functioning was measured with the Mini-Mental State Examination. ${ }^{42}$

\section{Statistical analyses}

Descriptive statistics were weighted according to age and gender. Probability weights were computed by dividing 5-year age and gender strata proportions in 1997, 2000 and 2007 by proportions of the same strata in 2003. For analysis of trends, generalised estimating equation analysis was used, which corrects for the fact that individuals were included in multiple waves. ${ }^{43}$ Binomial logit models were applied for three dichotomous outcomes: having or not having within 36 months after the interview: (1) one or more day admissions, (2) one or more overnight admissions and (3) one or more acute overnight admissions. An independent time variable represented the study years $(0,3,7$ and 10 years). All models were based on complete cases and they were age-related and gender-adjusted.

Four blocks of independent variables were included to examine their contribution to time trends in hospital admission. These blocks included the demographic, psychosocial, lifestyle and health status variables that showed associations (significant at $\mathrm{p}<0.20$ ) with the outcome in age-adjusted and gender-adjusted models. The blocks were entered in order from most distal (demographic) to most proximal (physical health 
Table 1 Study variables

\begin{tabular}{ll}
$\begin{array}{l}\text { Hospital registry (LMR) } \\
\text { variables }\end{array}$ & Measurement/definition \\
\hline $\begin{array}{l}\text { Outcome variables } \\
\text { Hospital admission } \\
\text { Day admission }\end{array}$ & $\begin{array}{l}\text { Admitted at least once within } 36 \text { months follow-up } \\
\text { At least one planned admission during the day within }\end{array}$ \\
Overnight admission & $\begin{array}{l}36 \text { months follow-up } \\
\text { At least one overnight admission (planned or acute) } \\
\text { within } 36 \text { months follow-up }\end{array}$ \\
Acute overnight & At least one acute overnight admission within \\
admission & 36 months follow-up
\end{tabular}

Level of measurement Range/categories/unit

Dichotomous Yes/no

Dichotomous Yes/no

Dichotomous Yes/no

Dichotomous Yes/no

Level of

measurement Range/categories/unit

\section{LASA variables \\ Demographic variables}

Measurement/definition

Age

Gender

Education in years

Categories: 9 levels of education attained, recoded into education in years

Income

Net monthly income in Euros. Income level of the second wave onwards was corrected for inflation (on average $2.3 \%$ per year). Net monthly income of respondents living with a partner was multiplied by 0.7 , to make their income comparable with that of one-person households.

Marital status

Urbanisation level

Categories: unmarried, married, divorced, widowed Data are provided by Statistics Netherlands.

Categories: 5 'very highly (>2500)'; 4 'highly

(1500-2500)'; 3 'somewhat (1000-1500)'; 2 'little (500-1000)'; 1 'not (<500)'

Institutionalised

Categories: independent housing, residential home, nursing home--somatic, nursing home-

psychogeriatric

\section{Psychosocial factors}

Network size

Received instrumental support

Received emotional support

\section{Mastery}

Social loneliness

Emotional loneliness

Lifestyle factors

Alcohol intake

Body mass index

Smoking
Number of network members identified by the respondent in 7 types of relationships

Four questions were asked about the relationships with a maximum of 9 network members with whom contact was most frequent. Instrumental support received: how often during the previous year the respondent had received help with daily chores around the house, such as preparing meals, cleaning the house, transportation and small repairs. Emotional support received: how often during the previous year they had talked to their network member about personal experiences and feelings. Categories: never (1), rarely (2), sometimes (3) or often (4) Pearlin Mastery scale ${ }^{27}$

5 items of the 11-item scale De Jong Gierveld ${ }^{29}$ 6 items of the 11 -item scale De Jong Gierveld ${ }^{29}$

Self-reported number of days per week respondents usually drankxthe number of glasses each time Measured weight (in kilogram)/height (in metres) squared

Self-reported smoking status. If respondents had stopped more than 20 years ago, they were categorised as non-smokers, since studies have shown similar mortality risks for those who stopped more than 20 years ago, compared with non-smokers. ${ }^{30}$

\section{Continuous 65-88 years}

Dichotomous Female/male

Continuous 5-18 years

Continuous $\quad 334-2270$ Euros

Dichotomous Married/not married Continuous 1-5

Dichotomous Institutionalised/living independently

$\begin{array}{ll}\text { Continuous } & 0-67 \\ \text { Continuous } & 0-36 \\ \text { Continuous } & 0-36\end{array}$

Continuous

Continuous

Continuous

Continuous

Continuous

Nominal
$5-25$
$0-5$
$0-6$

0-77 glasses/week

$\mathrm{kg} / \mathrm{m}^{2}$

Non-smoker/former smoker/current smoker 
Table 1 Continued

\section{LASA variables}

Sports physical activity

Non-sports physical activity

\section{Health factors}

Chronic diseases

Functional limitations

Self-rated health

Contact with general practitioner Contact with medical specialist

Physical performance

Polypharmacy

Systolic and diastolic BP

Depressive symptoms Cognitive functioning

\section{Measurement/definition}

Self-reported frequency $\times$ duration of sports activities. If the frequency or the time spent on the activity was missing, we imputed these by substituting with gender-specific and activity-specific means.

Self-reported frequency $x$ duration of non-sports activities. If the frequency or the time spent on the activity was missing, we imputed these by substituting with gender-specific and activity-specific means.

Self-reported presence of chronic non-specific lung disease, cardiac disease, peripheral arterial disease, stroke, diabetes mellitus, arthritis, cancer and a maximum of 2 other diseases that had been present for at least 3 months ${ }^{33}$

Self-reported number of activities out of 6 that respondents had difficulty performing ${ }^{34} 35$

Categories: very good (1), good (2), fair (3), sometimes good, sometimes bad (4), poor (5) ${ }^{36}$

Self-reported contact with a general practitioner in the previous 6 months

Self-reported contact with a medical specialist in the previous 6 months

Time in seconds measured for 3 performance-based tests (walking speed, ability to rise from a chair and putting on and taking off a cardigan). Sum scores of test-specific quartiles ranged from 0 to 12 , with 12 indicating the best performance. ${ }^{37}$

The number of drugs used was recorded from the medicine containers in the home of the respondents.

Polypharmacy was defined as having $\geq 5$ vs $<5$ drugs prescribed. ${ }^{39} 40$

Measurements were performed in sitting position. If multiple BP measurements were available (waves 2001-2002 and 2005-2006), only the first measurement was used to make the measurements comparable across waves.

Center for Epidemiologic Studies Depression Scale ${ }^{41}$ Mini-Mental State Examination ${ }^{42}$
Level of measurement Range/categories/unit

Continuous $\min /$ day

Continuous $\min /$ day

Continuous 0-9

Continuous $\quad 0-6$

Continuous 1-5

Dichotomous Yes/no

Dichotomous Yes/no

Continuous $\quad$ 0-12

Dichotomous $\quad \geq 5$ vs $<5$

Continuous $\mathrm{mm} \mathrm{Hg}$

Continuous $\quad 0-60$

Continuous $\quad 0-30$

BP, blood pressure; LASA, Longitudinal Aging Study Amsterdam; LMR, Landelijke Medische Registratie.

status) determinants. ${ }^{10}$ Their contribution was assessed by calculating the percentages decline or improvement in the coefficient for time after including them in the regression models. If the regression coefficient of time changed more than $10 \%$ after entering a block, each variable in the block was entered separately to assess which factor mostly accounted for the effect. Analyses were conducted using STATA V.14 (StataCorp, 2015).

\section{RESULTS}

The age-adjusted and gender-adjusted percentage of older adults with one or more hospital admissions within 36 months after their interview increased from $42.8 \%$ in 1997 to $53.4 \%$ in 2007 (table 2). Underlying this trend is a more than doubled percentage that experienced a day admission (from $12.3 \%$ to $28.3 \%$ ), and a slightly increased percentage with one or more overnight admissions over time (percentage increased from $38.1 \%$ to $39.7 \%$ ). The last increase concerned only acute admissions. Acute admission showed a curvilinear trend: it increased in particular after the year 2003. During the study period, a sharp decrease was observed in the length of stay, both in the average stay per overnight admission and in the total hospital days (day or overnight) within a period of 36 months.

Increasing trends were observed in education and income levels, the prevalence of being married, network size and the level of support received (table 3). The level of loneliness (both social and emotional) decreased over time. Lifestyle factors show a mixed trend: BMI increased and time spent on non-sports PA decreased, but the 
Table 2 Descriptives-dependent variables ${ }^{*}$

\begin{tabular}{|c|c|c|c|c|c|}
\hline & $\begin{array}{l}1997 \\
\mathrm{~N}=1692 \\
\text { Per cent/mean } \\
\text { (SD) }\end{array}$ & $\begin{array}{l}2000 \\
N=1474 \\
\text { Per cent/mean } \\
\text { (SD) }\end{array}$ & $\begin{array}{l}2003 \\
\mathrm{~N}=1295 \\
\text { Per cent/mean } \\
\text { (SD) }\end{array}$ & $\begin{array}{l}2007 \\
N=1220 \\
\text { Per cent/mean } \\
\text { (SD) }\end{array}$ & $\begin{array}{l}p \text { for } \\
\text { trendt }\end{array}$ \\
\hline Female gender (\%, unweighted) & 53.3 & 55.7 & 55.2 & 55.8 & - \\
\hline Mean age (range 65-88) (unweighted) & $76.0(6.7)$ & $75.5(6.7)$ & $75.2(6.6)$ & $74.5(6.4)$ & - \\
\hline $\mathrm{N}$ with $\geq 1$ hospital admissions & $724(42.8)$ & $629(42.7)$ & $618(47.7)$ & $652(53.4)$ & $<0.001$ \\
\hline$\geq 1$ day admissions & 207 (12.3) & $253(17.2)$ & $299(23.1)$ & 345 (28.3) & $<0.001$ \\
\hline$\geq 1$ overnight admissions (acute and elective) & $645(38.1)$ & $501(34.0)$ & $480(37.1)$ & $484(39.7)$ & $<0.05$ \\
\hline$\geq 1$ acute & $375(58.1)$ & 305 (60.9) & $296(61.2)$ & $330(68.2)$ & $<0.001$ \\
\hline$\geq 1$ elective & $414(64.2)$ & $293(58.5)$ & $294(61.3)$ & $283(58.5)$ & NS \\
\hline Per admitted person & $N=724$ & $N=629$ & $N=618$ & $N=652$ & \\
\hline Number of day admissions & $2.1(2.2)$ & $2.1(2.4)$ & $2.4(3.0)$ & $2.7(4.8)$ & $<0.001$ \\
\hline Number of overnight admissions & $1.6(1.3)$ & $1.4(1.4)$ & $1.4(1.7)$ & $1.5(1.6)$ & NS \\
\hline Number of acute admissions & $0.8(1.0)$ & $0.7(0.9)$ & $0.7(0.9)$ & $0.8(1.2)$ & NS \\
\hline Number of elective admissions & $0.9(1.0)$ & $0.7(1.1)$ & $0.8(1.5)$ & $0.7(1.0)$ & $<0.01$ \\
\hline $\begin{array}{l}\text { Mean length of stay per overnight admission } \\
\text { (days) }\end{array}$ & $12.8(13.1)$ & $11.6(14.9)$ & $9.7(9.2)$ & $7.4(6.4)$ & $<0.001$ \\
\hline Total length of stay for all admissions (days) & $21.1(26.2)$ & $16.4(25.0)$ & $14.6(18.1)$ & $12.5(19.8)$ & $<0.001$ \\
\hline
\end{tabular}

${ }^{*}$ All outcomes are weighted to the age and gender distributions in 2001-2002.

†In age-adjusted and gender-adjusted models.

prevalence of smoking decreased and time spent on sports increased over time. Most health factors, including the number of chronic conditions, functional limitations, medication use, depressive symptoms and self-rated health, showed a worsening trend. In contrast, cognitive functioning improved and systolic BP decreased.

Tables 4, 5 and 6 demonstrate the time trends (ORs reflect the effect per year of the study) and potential explanatory factors in those admission types that increased during the study period. The pronounced increase in day admission risk was not explained by any of the individual characteristics, which can be observed from very small changes in the OR after adding the four blocks of determinants (table 4). The significant increase in overnight admission risk disappeared after selecting those respondents who had complete information on all predictors (table 5). Still, introducing the predictors by domain revealed several suppressive (positive percentages) and explanatory (negative percentages) effects. After taking into account these suppressors (eg, education, sports PA and smoking), the increase in overnight admission was larger: their favourable health effects have to some extent prevented a larger increase in admission risk. The explanatory factors (eg, polypharmacy, chronic disease and functional limitations) decreased the regression coefficients: they explain some of the increase in admission risk. It should be noted, however, that the ORs remain very small for the increase in overnight admissions. For acute overnight admissions, similar results were observed (table 6), except that the statistically significant trend now remained after including all predictors. It should be noted that contact with a general practitioner or medical specialist was not included in the final models, as they can be considered a pre-requisite for most hospital admissions. Similar results were obtained in models that did include these variables.

We expected that changes in one admission type would have an influence on the prevalence of others. Therefore, in the full model for day admission, we additionally included an indicator of having one or more overnight admissions, and in the models for total and acute overnight admissions we adjusted for having one or more day admission (see online supplementary appendix table S1). This adjustment only had a minor impact: only the increase in acute admission risk over time was attenuated after adjusting for day admission risk.

\section{DISCUSSION}

We found a $10 \%$ point increase in the share of older adults who experienced one or more hospital admissions within 36 months after their interview: from $43 \%$ in 1995 to $53 \%$ in 2007 . A substantial contribution to this increase was made by day admissions, a type of care that shows a sharp increase in volume: the share of older adults with one or more day admissions increased from $12 \%$ to $28 \%$. This trend in day admission risk was not explained by changes in any of the demographic, psychosocial, lifestyle or health characteristics. However, the increase in acute overnight admission risk did show a relationship with worsening trends in health.

This study focused on individual-level characteristics, other than age and gender, which were controlled for, and not on higher level changes such as changes in general practitioner and hospital care data. Regardless, our results also reflect policy and organisational changes in medical care in the Netherlands. First, regarding the type of hospital admission, diagnostics and treatments of 
Table 3 Descriptives-independent variables*

\begin{tabular}{|c|c|c|c|c|c|}
\hline & $\begin{array}{l}1997 \\
N=1692 \\
\text { Per cent/mean } \\
\text { (SD) }\end{array}$ & $\begin{array}{l}2000 \\
N=1474 \\
\text { Per cent/mean } \\
\text { (SD) }\end{array}$ & $\begin{array}{l}2003 \\
\mathrm{~N}=1295 \\
\text { Per cent/mean } \\
\text { (SD) }\end{array}$ & $\begin{array}{l}2007 \\
\mathrm{~N}=1220 \\
\text { Per cent/mean } \\
\text { (SD) }\end{array}$ & $\begin{array}{l}p \text { for } \\
\text { trend }\end{array}$ \\
\hline \multicolumn{6}{|l|}{ Demographic variables } \\
\hline Education in years $(5-18)$ & $8.8(3.3)$ & $9.0(3.2)$ & $9.2(3.3)$ & $9.6(3.3)$ & $<0.001$ \\
\hline Income & $963(404)$ & 988 (393) & $1027(359)$ & $1052(319)$ & $<0.001$ \\
\hline Married & 53.4 & 53.6 & 55.4 & 59.7 & $<0.001$ \\
\hline Urbanisation level (1-5) & $3.2(1.5)$ & $3.1(1.4)$ & $3.0(1.4)$ & $3.0(1.4)$ & $<0.01$ \\
\hline Institutionalised & 5.1 & 3.8 & 3.8 & 2.8 & $<0.05$ \\
\hline \multicolumn{6}{|l|}{ Psychosocial factors } \\
\hline Network size (0-67) & $14.1(8.3)$ & $14.4(8.6)$ & $15.0(8.6)$ & $16.0(9.1)$ & $<0.001$ \\
\hline Received instrumental support (0-36) & $14.8(6.7)$ & $14.6(6.7)$ & $15.1(6.5)$ & $15.7(6.7)$ & $<0.001$ \\
\hline Received emotional support (0-36) & $20.7(8.3)$ & $20.7(7.9)$ & $21.9(7.9)$ & $22.1(7.7)$ & $<0.001$ \\
\hline Mastery (5-25) & $17.1(3.4)$ & $17.2(3.4)$ & $17.2(3.4)$ & $17.3(3.3)$ & NS \\
\hline Social loneliness (0-5) & $1.1(1.4)$ & $1.1(1.4)$ & $1.0(1.4)$ & $0.9(1.4)$ & $<0.05$ \\
\hline Emotional loneliness (0-6) & $1.3(1.8)$ & $1.3(1.8)$ & $1.2(1.7)$ & $1.1(1.7)$ & $<0.01$ \\
\hline \multicolumn{6}{|l|}{ Lifestyle factors } \\
\hline Alcohol intake (0-77 glasses per week) & $7.5(11.5)$ & $6.8(9.6)$ & $7.2(9.5)$ & $7.6(10.3)$ & NS \\
\hline Body mass index $\left(\mathrm{kg} / \mathrm{m}^{2}\right)$ & $26.9(4.2)$ & $27.3(4.2)$ & $27.4(4.2)$ & $27.5(4.3)$ & $<0.001$ \\
\hline Non-smoker & 60.8 & 66.9 & 67.5 & 68.8 & $<0.01$ \\
\hline Former & 19.7 & 17.1 & 17.3 & 17.4 & NS \\
\hline Current & 19.5 & 15.9 & 15.2 & 13.9 & $<0.001$ \\
\hline Sports physical activity (min/day) & $10.5(24.1)$ & $13.5(29.4)$ & $18.5(33.2)$ & $19.8(31.7)$ & $<0.001$ \\
\hline Non-sports physical activity (min/day) & $137.2(94.3)$ & $139.2(95.3)$ & $136.6(100.1)$ & $129.2(98.9)$ & $<0.01$ \\
\hline \multicolumn{6}{|l|}{ Health factors } \\
\hline Chronic diseases (0-9) & $1.6(1.2)$ & $1.7(1.3)$ & $1.7(1.2)$ & $1.8(1.2)$ & $<0.001$ \\
\hline Functional limitations (0-6) & $1.6(1.9)$ & $1.6(1.9)$ & $1.7(1.9)$ & $1.8(1.9)$ & $<0.001$ \\
\hline Self-rated health $(1-5)$ & $2.45(1.0)$ & $2.42(0.9)$ & $2.46(0.9)$ & $2.49(0.9)$ & $<0.01$ \\
\hline Contact with general practitioner & 79.1 & 83.8 & 81.5 & 81.1 & NS \\
\hline Contact with medical specialist & 50.7 & 51.8 & 53.4 & 53.0 & $<0.05$ \\
\hline Physical performance (0-12) & $7.0(2.7)$ & $6.8(2.7)$ & $7.0(2.6)$ & $7.4(2.6)$ & NS \\
\hline Polypharmacy ( $\geq 5$ vs $<5$ ) & 16.6 & 22.6 & 24.1 & 31.0 & $<0.001$ \\
\hline Systolic blood pressure $(\mathrm{mm} \mathrm{Hg})$ & $153.1(26.1)$ & $152.6(25.0)$ & $148.3(25.5)$ & $149.6(25.4)$ & $<0.001$ \\
\hline Diastolic blood pressure $(\mathrm{mm} \mathrm{Hg})$ & $83.3(13.6)$ & $83.0(12.2)$ & $82.4(13.3)$ & $82.9(13.7)$ & NS \\
\hline Depressive symptoms (0-60) & $8.4(8.1)$ & $8.7(7.6)$ & $9.2(7.5)$ & $8.6(7.3)$ & $<0.001$ \\
\hline Cognitive functioning $(0-30)$ & $26.6(3.3)$ & $26.9(3.1)$ & $27.0(3.2)$ & $27.2(2.7)$ & $<0.001$ \\
\hline
\end{tabular}

a wide range of diseases are increasingly being performed during day admissions instead of during overnight admissions. ${ }^{144}$ Second, budgetary constraints that had resulted, among other things, in long waiting lists were relaxed in 2001. These budgetary constraints did not concern primary care, but hospital care, for the most part, inpatient hospital care. In particular, the shift in overnight hospital admissions, from a decrease before the year 2000 to an increase after that, coincides with this development. Third, in 2005, a new financing system for hospitals was introduced. The Diagnosis Treatment Combination system (Diagnose Behandel Combinatie (DBC), similar to diagnosis-related groups (DRGs)) substantially increased the incentive for Dutch hospitals to shorten lengths of stay. Indeed, substantial decreases in length of stay of overnight admissions have been reported. ${ }^{6}$ At the same time, this development to a patient-based payment without a fixed budget ceiling may have stimulated healthcare spending. ${ }^{45}$ An increase in healthcare spending may be reflected in an increase in the share of respondents who had contact with a medical specialist during our study period.

We have argued that the increase in hospital admission risk that was found relates to the aforementioned developments. Still, we found that the proportion of older people who experienced an overnight admission in general did not increase, while the proportion of those who experienced an acute overnight admission did. This finding refines our hypothesis in that the increase in disease burden has only contributed to the growing use of acute hospital care over time. A report on out-of-hours general practitioner care in the Netherlands ${ }^{46}$ indeed showed that more acute cases have been presented at these units over the past decade.

Chronic diseases, medication use, functional limitations and poor self-rated health were shown to be 
predictive of hospitalisation in previous studies. ${ }^{14} 4748$ All these health indicators showed worsening trends in our study, partly corroborating findings from previous research. ${ }^{17} 1849$ An increase in chronic conditions in one person (multimorbidity) is frequently accompanied by an acute event that may lead to acute hospitalisation. ${ }^{50}$ An increase in medication prescription has been reported for older people in the UK and Italy as well. ${ }^{40}$ Having a higher number of drugs prescribed

\section{Table 4 Time trend in day admission and explanatory} factorst

\begin{tabular}{|c|c|c|}
\hline & OR $(95 \% \mathrm{Cl})$ & $\begin{array}{l}\text { Change in } \\
\text { regression } \\
\text { coefficient } \\
(\%) \ddagger\end{array}$ \\
\hline Time in years $\S$ & $1.105(1.083 \text { to } 1.127)^{\star * *}$ & \\
\hline +Demographics & $1.104(1.082 \text { to } 1.126)^{\star \star \star}$ & -1 \\
\hline +Psychosocial†† & $1.101(1.079 \text { to } 1.123)^{\star \star \star}$ & -3 \\
\hline +Lifestyleł‡ & $1.103(1.081 \text { to } 1.126)^{\star \star \star}$ & +2 \\
\hline+ Health status $\dagger \dagger \dagger$ & $1.097(1.074 \text { to } 1.120)^{\star \star \star}$ & -5 \\
\hline \multicolumn{3}{|c|}{$\begin{array}{l}{ }^{*} \mathrm{p}<0.05 ;{ }^{* *} \mathrm{p}<0.01 ;{ }^{* \star *} \mathrm{p}<0.001 \text {. } \\
\dagger \mathrm{N}=4036 \text { observations from a total of } 2010 \text { respondents. } \\
\ddagger \text { After adding this block, compared with a model with all } \\
\text { previously entered blocks. } \\
\text { \$Adjusted for age and gender. } \\
\text { ๆlnstitutionalised, marital status, urbanisation. } \\
\text { ††Network size, income, instrumental and emotional support. } \\
\text { ††Sports physical activity and smoking. } \\
\text { ††Chronic diseases, functional limitations, self-rated health, } \\
\text { physical performance, polypharmacy, systolic and diastolic blood } \\
\text { pressure, and cognitive functioning. }\end{array}$} \\
\hline
\end{tabular}

was shown to be independently associated with non-elective hospital admissions. ${ }^{47}$ Self-rated health explained some of the increases in admission risk, which might be due to it being a proxy for health factors that are not captured by more specific measures of disease and functioning. ${ }^{53}$ Other factors that showed an increase during the study period, which are associated with a higher risk of hospital admission and poor outcomes of hospitalisation, were mean body mass index and depressive symptoms. ${ }^{54} 55$

The increase in disease burden may be due to improved survival, particularly among older adults with chronic diseases. ${ }^{56} 57$ This trend, which is positive in itself, may have led to more complex cases in recent years. This complexity may increase the unpredictability of acute events, and thus including a broad set of health factors might not fully explain the increasing trend in acute admissions. An increase in acute admissions may also be an effect of shorter length of stay, through an increasing need for readmissions. However, it appears from our results that more people experience an admission, rather than some people experiencing more admissions. Discussion is still ongoing on the extent to which a decrease in the length of stay is associated with quality of care and readmission rates. ${ }^{3} 58$ Finally, increases in acute admissions may have resulted from a shift of emergency department (ED) presentations towards the end of the day, which leads more often to an admission. The extent to which this has played a role in our study remains uncertain.

A recent study from the UK reported that among those aged 65-84 years, disease prevalence and

Table 5 Time trend in overnight hospital admission and explanatory factors $†$

\begin{tabular}{|c|c|c|c|c|}
\hline & OR $(95 \% \mathrm{Cl})$ & $\begin{array}{l}\text { Change in } \\
\text { regression } \\
\text { coefficient }(\%) \ddagger\end{array}$ & Explanatory factors & $\begin{array}{l}\text { Change in } \\
\text { regression } \\
\text { coefficient (\%)§ }\end{array}$ \\
\hline Time in yearsף & $1.013(0.996$ to 1.030$)$ & & & \\
\hline +Demographics & $1.016(0.999$ to 1.034$)$ & +23 & $\begin{array}{l}\text { Education } \\
\text { Urbanisation }\end{array}$ & $\begin{array}{r}+15 \\
+8\end{array}$ \\
\hline +Psychosocial†† & $1.016(0.999$ to 1.034$)$ & -0 & & \\
\hline +Lifestyle & $1.019(1.001 \text { to } 1.037)^{*}$ & +19 & $\begin{array}{l}\text { BMI } \\
\text { Non-sports PA } \\
\text { Sports PA } \\
\text { Smoking }\end{array}$ & $\begin{array}{r}-6 \\
-6 \\
+19 \\
+13\end{array}$ \\
\hline +Health status & 1.004 (0.985 to 1.022$)$ & -21 & $\begin{array}{l}\text { Chronic diseases } \\
\text { Functional limitations } \\
\text { Self-rated health } \\
\text { Physical performance } \\
\text { Polypharmacy }(\geq 5 \text { vs }<5) \\
\text { Systolic blood pressure } \\
\text { Diastolic blood pressure } \\
\text { Depressive symptoms }\end{array}$ & $\begin{array}{r}-37 \\
-37 \\
-21 \\
-5 \\
-68 \\
-5 \\
-5 \\
-5\end{array}$ \\
\hline $\begin{array}{l}{ }^{*} \mathrm{p}<0.05 ;{ }^{* *} \mathrm{p}<0.01 ;{ }^{*} \\
\dagger \mathrm{N}=3809 \text { observatio } \\
\ddagger \text { After adding this blc } \\
\S \text { After adding this co } \\
\text { ๆAdjusted for age an } \\
+\dagger \text { Network size, incc } \\
\text { BMI, body mass ind }\end{array}$ & $\begin{array}{l}001 . \\
\text { m a total of } 1925 \text { responden } \\
\text { ompared with a model with } \\
\text { e, compared with a model } \\
\text { der. } \\
\text { nastery, instrumental suppo } \\
\text {, physical activity. }\end{array}$ & $\begin{array}{l}\text { viously entered block } \\
\text { previously entered b } \\
\text { tional and social lon }\end{array}$ & & \\
\hline
\end{tabular}


over time. If our findings reflect greater demand for hospital admission in the older population, this has implications for healthcare planning as well as for older adults' well-being. Therefore, future studies should further address the relative contributions of changes in health policy and in population health on hospital care usage.

Acknowledgements The Longitudinal Aging Study Amsterdam is largely funded by the Ministry of Health, Welfare and Sport of the Netherlands. Additional funding for this research was obtained from the Netherlands Gerontology Association (NVG). The authors acknowledge Dutch Hospital Data for permission to use the DHDR hospital data.

Contributors HG, DJHD and MH conceived and designed the work and contributed to acquisition for the work. $\mathrm{HG}$ analysed the data and drafted the manuscript. DJHD, RTdJ, JWPFK and MH helped interpret the data and revised the paper critically for important intellectual content. All authors approved the version to be published, and are accountable for all aspects of the work in ensuring that questions related to the accuracy or integrity of any part of the work are appropriately investigated and resolved.

Funding $\mathrm{MH}$ was supported by a fellowship from the Dutch Organization for Scientific Research, no 452-11-017.

Competing interests None declared.

Ethics approval Medical Ethics Committee of the VU University Medical Center (VUMC).

Provenance and peer review Not commissioned; externally peer reviewed.

Data sharing statement No additional data are available.

Open Access This is an Open Access article distributed in accordance with the Creative Commons Attribution Non Commercial (CC BY-NC 4.0) license, which permits others to distribute, remix, adapt, build upon this work noncommercially, and license their derivative works on different terms, provided the original work is properly cited and the use is non-commercial. See: http:// creativecommons.org/licenses/by-nc/4.0/

\section{REFERENCES}

1. Statistics Netherlands. http://statline.cbs.nl/Statweb/publication/? $\mathrm{VW}=\mathrm{T} \& \mathrm{DM}=\mathrm{SLNL} \& \mathrm{PA}=83039 \mathrm{NED}$ (accessed 30 Oct 2015).

2. OECD. Average length of stay in hospitals. OECD Publishing. Health at a Glance 2011: OECD Indicators, 2011.

3. Kaboli PJ, Go JT, Hockenberry J, et al. Associations between reduced hospital length of stay and 30-day readmission rate and mortality: 14-year experience in 129 Veterans Affairs Hospitals. Ann Intern Med 2012;157:837-45.

4. Creditor MC. Hazards of hospitalization of the elderly. Ann Intern Med 1993;118:219-23.

5. Liotta G, Mancinelli S, Scarcella P, et al. Determinants of acute hospital care use by elderly patients in Italy from 1996 to 2006. Arch Gerontol Geriatr 2012;54:e364-9.

6. Borghans I, Heijink R, Kool T, et al. Benchmarking and reducing length of stay in Dutch hospitals. BMC Health Serv Res 2008;8:220.

7. Kalra AD, Fisher RS, Axelrod P. Decreased length of stay and cumulative hospitalized days despite increased patient admissions and readmissions in an area of urban poverty. J Gen Intern Med 2010;25:930-5

8. Oksuzyan A, Jeune B, Juel K, et al. Changes in hospitalisation and surgical procedures among the oldest-old: a follow-up study of the entire Danish 1895 and 1905 cohorts from ages 85 to 99 years. Age Ageing 2013;42:476-81.

9. Martin AB, Hartman M, Whittle L, et al., National Health Expenditure Accounts Team. National health spending in 2012: rate of health spending growth remained low for the fourth consecutive year. Health Aff (Millwood) 2014;33:67-77.

10. Andersen R, Newman JF. Societal and individual determinants of medical care utilization in the United States. Milbank Q. Published Online First: 18 Nov 2005. doi:10.1111/j.1468-0009.2005.00428.x

11. Mackenbach JP, Slobbe L, Looman CW, et al. Sharp upturn of life expectancy in the Netherlands: effect of more health care for the elderly? Eur J Epidemiol 2011;26:903-14.
12. Kelly M, Sharp L, Dwane F, et al. Factors predicting hospital length-of-stay and readmission after colorectal resection: a population-based study of elective and emergency admissions. BMC Health Serv Res 2012;12:77.

13. Li CL, Chu SJ, Sheu JT, et al. Impact of physical activity on hospitalization in older adults: a nationwide cohort from Taiwan. Arch Gerontol Geriatr 2011:53:141-5.

14. Wolinsky FD, Culler SD, Callahan CM, et al. Hospital resource consumption among older adults: a prospective analysis of episodes, length of stay, and charges over a 7-year period. J Gerontol 1994;49:S240-52.

15. Jimenez-Garcıa R, Villanueva-Martınez M, Fernandez-de-Las-Penas $\mathrm{C}$, et al. Trends in primary total hip arthroplasty in Spain from 2001 to 2008: evaluating changes in demographics, comorbidity, incidence rates, length of stay, costs and mortality. BMC Musculoskelet Disord 2011;12:43.

16. Bueno $\mathrm{H}$, Ross JS, Wang Y, et al. Trends in length of stay and short-term outcomes among Medicare patients hospitalized for heart failure, 1993-2006. JAMA 2010;303:2141-7.

17. Parker MG, Thorslund M. Health trends in the elderly population: getting better and getting worse. Gerontologist 2007;47:150-8.

18. Crimmins EM, Beltrán-Sánchez $\mathrm{H}$. Mortality and morbidity trends: is there compression of morbidity? J Gerontol B Psychol Sci Soc Sci 2011;66:75-86.

19. Hoeymans N, Wong A, van Gool CH, et al. The disabling effect of diseases: a study on trends in diseases, activity limitations, and their interrelationships. Am J Public Health 2012;102:163-70.

20. van Gool CH, Picavet HSJ, Deeg DJ, et al. Trends in activity limitations: the Dutch older population between 1990 and 2007. Int J Epidemiol 2011;40:1056-67.

21. Chatterji S, Byles J, Cutler D, et al. Health, functioning, and disability in older adults - present status and future implications. Lancet 2015;385:563-75

22. Huisman M, Poppelaars J, van der Horst M, et al. Cohort profile: the longitudinal aging study Amsterdam. Int $\mathrm{J}$ Epidemio 2011;40:868-76.

23. The American Association for Public Opinion Research. Standard Definitions: Final Dispositions of Case Codes and Outcome Rates for Surveys. www.aapor.org (accessed 11 Aug 2016)

24. de Bruin A, Kardaun J, Gast F, et al. Record linkage of hospital discharge register with population register: Experiences at Statistics Netherlands. Stat $J$ United Nations Econ Comm Europe 2004:21:23-32.

25. Paas GRA, Veenhuizen KCW. Onderzoek naar de betrouwbaarheid van de LMR. Prismant, 2002.

26. Koster A, Bosma H, Broese van Groenou MI, et al. Explanations of socioeconomic differences in changes in physical function in older adults: results from the Longitudinal Aging Study Amsterdam. BMC Public Health 2006;6:244-59.

27. Pearlin LI, Schooler C. The structure of coping. J Health Soc Behav 1978;19:2-21.

28. van Tilburg T. Losing and gaining in old age: changes in personal network size and social support in a four-year longitudinal study. $J$ Gerontol B Psychol Sci Soc Sci 1998;53:S313-23.

29. de Jong-Gierveld J, Kamphuis F. The development of a Rasch-type loneliness scale. Appl Psychol Meas 1985;9:289-99.

30. Gellert C, Schöttker B, Brenner H. Smoking and all-cause mortality in older people: systematic review and meta-analysis. Arch Intern Med 2012;172:837-44.

31. Pluijm SM, Visser M, Puts MT, et al. [Unhealthy lifestyles during the life course: association with physical decline in late life]. Tijdschr Gerontol Geriatr 2006;37:226-36.

32. Stel VS, Smit JH, Pluim SM, et al. Comparison of the LASA Physica Activity Questionnaire with a 7-day diary and pedometer. J Clin Epidemiol 2004;57:252-8.

33. Kriegsman DM, Penninx BW, van Eijk JT, et al. Self-reports and general practitioner information on the presence of chronic diseases in community dwelling elderly. A study on the accuracy of patients self-reports and on determinants of inaccuracy. J Clin Epidemiol 1996;49:1407-17.

34. Bisschop MI, Kriegsman DMW, Beekman ATF, et al. Chronic diseases and depression: the modifying role of psychosocial resources. Soc Sci Med 2004;59:721-33.

35. Bisschop MI, Kriegsman DM, van Tilburg TG, et al. The influence of different social ties on decline in physical functioning among older people with and without chronic diseases: the Longitudinal Aging Study Amsterdam. Aging Clin Exp Res 2003;15:164-73.

36. Galenkamp H, Braam AW, Huisman M, et al. Somatic multimorbidity and self-rated health in the older population. J Gerontol B Psychol Sci Soc Sci 2011;66B:380-6. 
37. Penninx BW, Deeg DJ, van Eijk JT, et al. Changes in depression and physical decline in older adults: a longitudinal perspective. $J$ Affect Disord 2000;61:1-12.

38. Maher RL, Hanlon J, Hajjar ER. Clinical consequences of polypharmacy in elderly. Expert Opin Drug Saf 2014;13:57-65.

39. Franchi C, Cartabia M, Risso P, et al. Geographical differences in the prevalence of chronic polypharmacy in older people: eleven years of the EPIFARM-Elderly Project. Eur J Clin Pharmacol 2013;69:1477-83.

40. Mazzaglia G, Roti L, Corsini G, et al. Screening of older community-dwelling people at risk for death and hospitalization: the Assistenza Socio-Sanitaria in Italia Project. J Am Geriatr Soc 2007;55:1955-60.

41. Radloff LS. The CES-D Scale: a self-report depression scale for research in the general population. Appl Psychol Meas 1977;3:385-401.

42. Folstein MF, Folstein SE, McHugh PR. "Mini-mental state". A practical method for grading the cognitive state of patients for the clinician. J Psychiatr Res 1975;12:189-98.

43. Twisk JWR. Applied longitudinal data analysis for epidemiology: a practical guide. New York: Cambridge University Press, 2003.

44. Wasowicz DK, Schmitz RF, Borghans HJ, et al. Growth potential of ambulatory surgery in the Netherlands. Ambul Surg 2000;8:7-11.

45. Wubulihasimu P, Gheorghe M, Slobbe L, et al. Trends in Dutch hospital spending by age and disease 1994-2010. Health Policy 2015;119:316-23.

46. InEen. Benchmarkbulletin Huisartsenposten 2013. Utrecht: InEen, 2014.

47. Damush TM, Smith DM, Perkins AJ, et al. Risk factors for nonelective hospitalization in frail and older adult, inner-city outpatients. Gerontologist 2004;44:68-75.

48. Clay OJ, Roth DL, Safford MM, et al. Predictors of overnight hospital admission in older African American and Caucasian Medicare beneficiaries. J Gerontol A Biol Sci Med Sci 2011;66:910-16.

49. Uijen $A A$, van de Lisdonk $E H$. Multimorbidity in primary care: prevalence and trend over the last 20 years. Eur $J$ Gen Pract 2008;14(Suppl 1):28-32.

50. Buurman BM, Frenkel WJ, Abu-Hanna A, et al. Acute and chronic diseases as part of multimorbidity in acutely hospitalized older patients. Eur J Intern Med 2016;27:68-75.

51. Payne RA, Abel GA, Guthrie B, et al. The effect of physical multimorbidity, mental health conditions and socioeconomic deprivation on unplanned admissions to hospital: a retrospective cohort study. CMAJ 2013;185:E221-8.

52. Melzer D, Tavakoly B, Winder RE, et al. Much more medicine for the oldest old: trends in UK electronic clinical records. Age Ageing 2015;44:46-53.

53. Jylhä M. What is self-rated health and why does it predict mortality? Towards a unified conceptual model. Soc Sci Med 2009;69:307-16.

54. Prina AM, Deeg D, Brayne C, et al. The association between depressive symptoms and non-psychiatric hospitalisation in older adults. PLOS ONE 2012;7:e34821.

55. Sadr Azodi O, Bellocco R, Eriksson K, et al. The impact of tobacco use and body mass index on the length of stay in hospital and the risk of post-operative complications among patients undergoing total hip replacement. J Bone Joint Surg Br 2006;88:1316-20.

56. Deeg Dorly JH, van Vliet Majogé JG, Kardaun Jan WPF, et al. Understanding the mortality decline at older ages. Improved life course or improved present period? Annu Rev Gerontol Geriatr 2013;33:259-91.

57. Peters F, Nusselder WJ, Mackenbach JP. A closer look at the role of healthcare in the recent mortality decline in the Netherlands: results of a record linkage study. J Epidemiol Community Health 2015;69:536-42.

58. Clarke A. Length of in-hospital stay and its relationship to quality of care. Qual Saf Health Care 2002;11:209-10.

59. Karampampa K, Andersson T, Drefahl S, et al. Does improved survival lead to a more fragile population: time trends in second and third hospital admissions among men and women above the age of 60 in Sweden. PLOS ONE 2014;9:e99034.

60. Karampampa K, Drefahl S, Andersson T, et al. Trends in age at first hospital admission in relation to trends in life expectancy in Swedish men and women above the age of 60. BMJ Open 2013;3:e003447.

61. Roberts DC, McKay MP, Shaffer A. Increasing rates of emergency department visits for elderly patients in the United States, 1993 to 2003. Ann Emerg Med 2008;51:769-74.

62. Pines JM, Mullins PM, Cooper JK, et al. National trends in emergency department use, care patterns, and quality of care of older adults in the United States. J Am Geriatr Soc 2013;61:12-17.

63. Miller S. The effect of insurance on emergency room visits: an analysis of the 2006 Massachusetts health reform. J Public Econ 2012;96:893-908.

64. Galenkamp H, Braam AW, Huisman M, et al. Seventeen-year time trend in poor self-rated health in older adults: changing contributions of chronic diseases and disability. Eur J Public Health 2013;23:511-17. 